\title{
Accelerating Transition Dynamics in City Regions: A Qualitative Modeling Perspective
}

\author{
Pieter Valkering ${ }^{1, *}$ (D) , Gönenç Yücel ${ }^{2}$ (D) , Ernst Gebetsroither-Geringer ${ }^{3}$, Karin Markvica ${ }^{3}$, \\ Erika Meynaerts ${ }^{1}$ and Niki Frantzeskaki ${ }^{4}$ \\ 1 VITO (Flanders Institute for Technological Research)/EnergyVille, 2400 Mol, Belgium; \\ erika.meynaerts@vito.be \\ 2 Boğaziçi University Istanbul, 34342 Istanbul, Turkey; gonenc.yucel@boun.edu.tr \\ 3 AIT Austrian Institute of Technology GmbH, 1220 Vienna, Austria; ernst.gebetsroither@ait.ac.at (E.G.-G.); \\ karin.markvica@ait.ac.at (K.M.) \\ 4 DRIFT (Dutch Research Institute For Transitions), Faculty of Social Sciences, Erasmus University Rotterdam, \\ 3000 DR Rotterdam, The Netherlands; n.frantzeskaki@drift.eur.nl \\ * Correspondence: pieter.valkering@vito.be; Tel.: +32-14-335-838
}

Received: 31 May 2017; Accepted: 12 July 2017; Published: 18 July 2017

\begin{abstract}
In this article, we take stock of the findings from conceptual and empirical work on the role of transition initiatives for accelerating transitions as input for modeling acceleration dynamics. We applied the qualitative modeling approach of causal loop diagrams to capture the dynamics of a single transition initiative evolving within its regional context. In doing so, we aim to address two key challenges in transition modeling, namely conceptualization, and the framing of empirical insights obtained for various case study regions in a consistent modeling framework. Our results show that through this systematic approach one can translate conceptual and qualitative empirical work into a transition model design. Moreover, the causal loop diagrams can be used as discussion tools to support dialogue among researchers and stakeholders, and may support a comparison of transition dynamics across case-study regions. We reflect on main limitations related to empirical model validation (lack of data) and to model structure (high level of aggregation), and describe next steps for moving from a qualitative single transition initiative to a quantitative multiple transition initiatives model.
\end{abstract}

Keywords: acceleration; sustainability transitions; transition initiatives; transition governance; qualitative modeling; causal loop diagrams

\section{Introduction}

It is increasingly recognized that achieving a sustainable, low-carbon society requires sustainability transitions, involving structural changes of thinking, doing and organizing across multiple societal domains [1]. Of the four phases (predevelopment, takeoff, acceleration and stabilization) identified in the transition literature [2,3], predevelopment and takeoff phases have received the most interest [4-6]. However, relatively little is known about how to accelerate transition dynamics, in particular with respect to the potential role of local transition initiatives as drivers of transformative change $[7,8]$. The EU FP7 project ARTS (Accelerating and Rescaling Transitions to Sustainability) aimed to address this knowledge and practice gap. ARTS analyzed the role of local transition initiatives (TIs) in driving acceleration dynamics in a number of European city regions, situated within their national and wider European contexts. Through a transdisciplinary approach, the project aimed to identify conditions, mechanisms and strategies through which TIs may contribute to an accelerated transition.

Previous work $[8,9]$ has focused on a conceptual understanding of the role of TIs in the acceleration of transition dynamics, highlighting five key mechanisms explained below: upscaling, 
replicating, partnering, instrumentalizing, and embedding. Elaborate case studies have been performed investigating how these mechanisms have materialized in five case-study city regions in Europe (Brighton, Budapest, Dresden, Genk and Stockholm) that all show early signs of acceleration dynamics across multiple low carbon domains (e.g., energy, transport, biodiversity). We build upon this work by designing models capturing transition acceleration dynamics with the aim to explore different strategies TIs and other actors may adopt to stimulate acceleration. Through this exercise we aim to facilitate the understanding of acceleration dynamics by providing an integrated and systemic view on the various causal relations and interactions at play.

The literature on modeling transition dynamics shows a number of recent applications (see [10-12] for overviews). Such types of transition models provide a clear added value in transition research complementary to qualitative empirical research methods more often used [8]. As described in Holtz et al. [10], these benefits can be summarized as (a) offering an analysis that is explicit, clear and systematic, (b) allowing inferences of dynamics in complex systems, and (c) allowing for experimentation that in real-life circumstances would be costly and are practically impossible to undertake. As such they can be useful for the further understanding of complex transition dynamics, for robustness analysis of different possible policy actions and for the facilitation of stakeholder processes.

Yet, key limitations currently remain [10], in this paper referred to as "challenges". The first relates to the conceptualization and implementation of transition models. Often, transition theory and frameworks only partly describe the dynamic relations modeling requires. Also, modelers often face the need to make ad-hoc assumptions to operationalize their models, which are not well underpinned and even often made in an obscure way. The second challenge relates to the validation of transition models. Transition models often contain a large number of free parameters that can only partly be determined from empirical data, due to practical constraints as well as the inherent qualitative nature of data needed. The third challenge relates to agency and contingency. Strategic actions of core actors strongly influence the transition dynamics of a system, but are fundamentally uncertain and difficult to capture in models in an endogenous way. The last challenge relates to expectations, results and communication. Even when being considered (by the modelers themselves) as a rather simple representation of complex realities, models tend to be perceived as being rather difficult to understand by other researchers, policy-makers and other stakeholders, also because time available for engaging with models is often limited. Balancing simplicity and detail, ensuring model trust, and avoiding misinterpretation of model results are thus challenges to overcome when aiming for impact.

The qualitative modeling approach discussed in this paper aims to address in particular the first two challenges of conceptualization and implementation and validation. It does so by translating conceptual and qualitative empirical work into a transition model design using causal loop diagrams (CLDs). This approach aims to provide an intermediary step between qualitative conceptual and empirical work on the one hand, and quantitative transition modeling approaches on the other. Although full integration is generally considered infeasible due to foundational differences in philosophies of science, bridging these qualitative and quantitative approaches is generally considered fruitful. Each approach has their own strengths and weaknesses, and they can complement and enrich each other as such [13-15].

We developed CLDs representing the dynamics of an individual transition initiative operating in a city-regional context. First, a generic CLD was developed representing the main relationships between main concepts in the system as discussed in the conceptual framework of acceleration dynamics adopted in ARTS. Following, the generic CLD was applied to the different case-study regions to derive updated and validated CLDs capturing specific regional dynamics. To represent acceleration strategies, we drew from the concept of leverage points of a system [16]. Based on this concept, acceleration strategies are in our research perceived as (sets of) planned activities that are undertaken to influence specific concepts in the CLD that in turn may drive the different acceleration mechanisms of upscaling, replicating, partnering, instrumentalizing, and embedding. 
In this paper, we present an overview of our methodology and results. We reflect on the main lessons learned in the modeling processes, highlight main limitations, and sketch out next steps towards the development of an agent-based model representing the interaction among TIs in a more detailed and quantitative way.

\section{Methodology}

\subsection{Modeling Transition Dynamics}

Sustainability transitions involve a complex dynamics of interrelated processes at multiple scales [1-3,17-19]. Modeling these dynamics poses an obvious challenge, which has been addressed in a number of recent applications (see [10-12] for overviews). A variety of approaches-usually based on systems dynamics and agent-based modeling paradigms, with in some cases stochastic elements-and specific application areas (energy, water, transport) have been explored. Chappin [20], for example, developed an agent-based model of socio-technical systems, typically capturing the interactions between actors and technologies in response to exogenous scenarios and policy interventions that was applied to the power sector, the Liquefied Natural Gas market, and consumer lighting. Dijk et al. [21] present an agent-based analysis of innovation diffusion in the field of car engine technology representing the co-evolution between technological innovation and social context through several feedback loops, such as economies of scale and the social construction of meaning. Li and Strachan [22] present a dynamic stochastic simulation of energy supply technology diffusion, capturing the influence of regime-actors (energy supply, residential, commercial, industrial, and transport), niche innovations (transition technologies, lifestyle changes) and macro-scale energy system drivers (economic growth, environmental policies, technology and fuel costs). De Haan et al. [23] present an exploratory modeling approach to simulate pathways of the uptake and phasing-out of solutions to societal needs. The model captures the institutionalization of solutions (cultural-cognitive, normative and regulative institutions), as well as the power dynamics among a regime and niches as changes in the so-called constellations of solutions, and was applied to a historical case of water management. Walrave and Raven [24] integrate the concept of technological innovation systems and multi-level-framework thinking into a system dynamics model. This model captures the dynamics among the four so-called "motors of innovation" (science and technology push, entrepreneurial, system building, and market) in combination with a key feedback loop representing regime resistance. Moallemi et al. [15], zoom in on the electricity sector, presenting a narrative-modeling approach of transition dynamics, in which transition narratives feed into the development of a systems dynamics model that in turn is used to underpin the narratives initially developed.

We address two main examples in more detail to set the context of our work. The first is the transition model of [25-28] developed in the EU MATISSE project. In this agent-based model, societal change is perceived as an ongoing competition between a currently established regime, and emerging and competing niches, in response to landscape changes. To this end, the model includes both collective agents (regimes and niches) and individual agents ("consumers" attached to either the regime or one of the niches) located on a practice space. In each time step, individual agents decide which collective agent to support, depending on their practice preference, as well as the collective agent's strength. The collective agents, from their side, move around (adapt) in practice space on the basis of specific strategies, and change state (transform, e.g., from "niche" to "empowered niche" to "regime") as their support changes. The dynamics is strongly driven by the so-called landscape signals-representing changes of e.g., worldview, macro-economy, physical infrastructure, natural environment and demographics- that induce an external pressure on individual agents to move in practice space.

Another example is the actor-option framework (AOF) for modeling socio-technical systems [29]. Based on case study analysis from the literature, this framework offers modular concepts for modeling transition dynamics composed of building blocks (i.e., actors and options) and a set of mechanisms specifying how these blocks interact and change. The first building block, i.e., the actor, thereby represents 
the social elements of the system. Actors are differentiated through a number of key aspects (preferences, references, and commitments) and different actor roles (regulators, providers, practitioners, opinion groups) that outline the impact on the system actors have. The second building block, i.e., the option, corresponds to alternatives the actors have to fulfill a certain societal function. Options are characterized by both embodied properties related to the techno-physical nature of an option, as well as disembodied properties related to the context in which the option functions. Finally, to explain transitional change in terms of endogenous processes of change, 10 generic mechanisms were proposed under three different groups: mechanisms on option change, on actors' knowledge, and on actors' identity.

We zoom in on how, in these two modeling examples, the challenges of conceptualization and implementation and validation [10] have been addressed. The conceptual framework of the Matisse model was dedicated to analyzing and simulating transition dynamics, while ensuring broad consistency with theoretical and empirical work [26]. After implementation, the model was applied among others to the analysis of personal (inland) transportation behavior in the UK [28]. This typically involved model parameterization and calibration in terms of appropriate starting conditions for regimes and niches, suitable practice dimensions, and representative landscape signals. The conceptual foundations of the AOF were developed by deduction based on an extensive set of case studies from innovation diffusion, socio-technical systems and societal transitions literature [29]. The framework was then used to model various transition processes, including the transition to steam-ships in British naval transportation, waste management in the Netherlands [30,31], and the ongoing transition in the Dutch electricity supply system [32]. Conceptual validation was performed by testing to what extent key processes of change in these three cases were adequately represented [29]. Moreover, the transition dynamics that were generated by these three models were tested against empirical data for behavioral validity.

Our approach towards conceptualization and implementation and validation has been quite different. Rather than departing from a model based conceptualization with case study application towards the end of the modeling exercise, we have attempted to develop a transition model in closer interaction with conceptual and empirical case study work using qualitative modeling to link the different methodological strands [33]. This is illustrated in Figure 1 and explained in more detail in Section 2.4. The qualitative model has been informed first by the ongoing work on the ARTS conceptual framework [9] centered on the five acceleration mechanisms, and in a second step by the case study analysis (also informed by the conceptual framework) performed in various case study regions $[8,34]$. The qualitative modeling in turn formed the basis for an agent-based model [35] that was further operationalized for interactive use with stakeholders as a simulation game. Both the simulation game and the qualitative models were used in stakeholder workshops with representatives of TIs and regional authorities as stakeholders [36]. Besides learning outcomes on acceleration dynamics and strategies, stakeholder feedback allowed for a validation of the developed models as learning tools $[37,38]$, and generated input for further model refinements. In the next sections we zoom in on the qualitative modeling approach in relation to the conceptual framework and case study analysis.

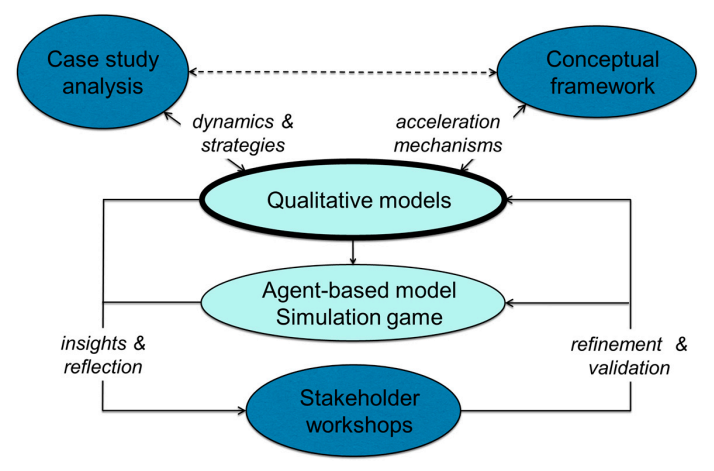

Figure 1. Qualitative modeling as intermediary step between qualitative conceptual and empirical work and quantitative transition modeling approaches. 


\subsection{Framing Acceleration Dynamics}

The conceptualization underlying of our model of acceleration dynamics departs from the notion of local sustainability transition initiatives (TIs) as main drivers of change. It distinguishes TIs as its "embedded unit of analysis", which emerge and interact with each other in a city region (referred to as the "case"), which in turn is embedded in a "multi-level governance context" [34]. To examine the role of TIs for accelerating sustainability transitions, the framework thus highlights the following dimensions:

1. the development of single TIs within the city region;

2. the interactions between different TIs within the city region;

3. the embeddedness of TIs in specific city-regional governance patterns;

4. the position of TIs within a multi-level governance context that spans across different spatial scales (i.e., subnational, national, transnational and European).

Consequently-based on a literature review of the fields of sustainability transition, transformative agency and urban governance-the conceptual framework distinguishes five acceleration mechanisms as follows [8,9]:

- Upscaling is the growth of members, supporters or users of a single TI in order to spread new ways of thinking, doing, and organizing (TDO).

- Replicating is the take up of new ways of TDO of one transition initiative by another transition initiative or different actors in order to spread out these new ways.

- Partnering is the pooling and/or complementing of resources, competences, and capacities in order to exploit synergies to support and ensure the continuity of the new ways of TDO.

- Instrumentalizing is tapping into and capitalizing on opportunities provided by the multi-level governance context of the city region in order to strengthen new ways of TDO locally. Concrete examples are fund raising or highlighting global sustainability trends (e.g., international attention for the importance of bees) for local outreach.

- Embedding is the alignment of old and new ways of TDO in order to integrate them into city-regional governance patterns.

Although the framework is very useful to frame acceleration dynamics, we also recognized some main shortcomings when approaching acceleration from a modeling perspective [33]. The main ones are that:

- There remains a need to operationalize the qualitative definition of acceleration dynamics into a set of concrete indicators.

- The high level of aggregation at which the conceptual framework describes the acceleration mechanisms poses limits to understanding the drivers and outcomes of the acceleration mechanisms at work. There is thus a need to disaggregate the description of dynamic processes to reveal the process pathways underlying the different mechanisms.

- The conceptual framework mainly covers the drivers of acceleration processes, but only weakly covers the preconditions and barriers to the five basic acceleration mechanisms.

\subsection{Investigating Acceleration Dynamics}

The empirical basis for our modeling work was based on in-depth case study research in various case study regions in Europe. Following Yin's [39] design principles (see [8,34]). This data gathering process involved first, an extensive mapping of TIs in the city region regardless of leadership or ownership of the initiative (public, corporate, civic or partnerships of those). Second, a selection was made of TIs that were actively working on environmental sustainability issues and operating in the city regions for more than 5 years so as to have established connections with other change agents and actors in the city and actively work. Then, in-person semi-structured interviews were conducted with selected 
TIs' members to examine the different ways TIs interact and connect with each other, the relationships they have with local government, the strategies they employ for reaching out to general public, ways of operating and organizing as well as which were barriers and opportunities for their operation in the city region. On average in every city region, 15-20 in-person interviews were conducted lasting 1-2 h. To complement the data gathered from the TIs' interviews, interviews with "helicopter viewers" (people with an overview of different TIs within the city region) were conducted to validate and further enrich the first findings from the TIs' interviews. In every city region there were between $2-5$ helicopter viewers' interviews conducted either by phone or in person. The data collected were analyzed using a tailored coding scheme that responded to the five acceleration mechanisms. The data collection lasted on average 5 months in every city region and the analysis of data required 3 months from every research team. The analysis of the data was then presented and further discussed in a series of participatory workshops attended by TIs, local government representatives, the helicopter viewers and urban experts from every city. The number of workshops realized in every city region varied between 2 to 5 workshops depending on the overall time planned per workshop (city teams chose workshop set ups between 4 to $8 \mathrm{~h}$ that fit the requirements and style of their own context). This process delivered a rich data set, describing the way and extent to which the five acceleration mechanisms are present in each city region. It reflected on the role of TIs in urban sustainability transition dynamics and their development and how they relate and interact with local governments and other relevant urban actors. It further identified opportunities and obstacles for their operation in practicing sustainability at the local context and how it relates to broader urban sustainability transition.

Despite the richness of the data, we also identified a number of limitations as a data set underpinning acceleration models. For example, the empirical analysis tended to focus on the current status quo, whereas modeling rather requires temporal data, i.e., covering the way things have been unfolding in the recent past. Insights were mostly qualitative where modeling requires as much as possible quantitative data. Furthermore, influence relations were not elicited in detail and, motivations underlying the activities the TIs undertake were not elicited during the interviews. These meant that the follow-up modeling work did require some level of interpretation and sometimes making bold assumptions.

\subsection{Towards Acceleration Models: A Qualitative Modeling Approach}

To overcome the limitations above, the modeling work has adopted a qualitative modeling approach as a basis for the further modeling work. Qualitative modeling was chosen to provide a common methodology based on which modelers and case-study researchers could collaborate to address the issues of conceptualization (such as disaggregate description of dynamic processes) and data gathering (such as the elicitation of influence relations) described above. In this approach, modelers and case-study researchers collaborated using the qualitative modeling technique of CLD to develop so-called single transition initiative (STI) models. STI models represent the dynamics of an individual TI operating in a city-regional context. The focus on the single TI directly follows from the conceptual framework, which adopts the TI as its embedded unit of analysis. Understanding the internal dynamics of an initiative and the implications of different acceleration mechanisms for its development and its interaction with the city regional context is thus of primary importance.

The STI model is developed in the form of a CLD that aims to capture the relationships between main concepts discussed in the conceptual framework with a visual representation. This way the model provides a structured systemic representation of the major processes included in the conceptual framework that drive the development of an initiative and their connection to other TIs, as well as the interplay of these processes. Compared to a purely verbal depiction of the proposed acceleration mechanisms, such a systemic representation is expected to highlight the drivers and dynamic processes that correspond to the five key mechanisms introduced in the conceptual framework, to foster dynamic thinking regarding how certain mechanisms may be interacting over time and to reveal factors that may potentially block them, and drivers (feedback loops) that may potentially counteract. 
To develop the STIs the following steps were taken:

1. A first version generic STI model was developed representing the main relationships between main concepts related to the state of a TI and to the state of the city-regional context within which the TI operates, as discussed in the conceptual framework of acceleration dynamics adopted in ARTS.

2. The generic version of the model was applied to the different case-study regions to yield case study specific models, based on the results from the in-depth case study analysis and further discussions with the case-study researchers. This served as a model validation, allowing modifying, adding or deleting concepts and relations in light of the empirical findings.

3. The case study specific models were reviewed for consistency and further used to derive the updated and validated generic STI model displayed in Annex A. Here, the main logic adopted was that processes and relations that are supported by multiple sources (potential sources being regional in-depth case study reports as empirical support, and the conceptual framework as the theoretical support) should be incorporated.

\subsection{Towards Acceleration Strategies: Leverage Points of the System}

A particular aim of the modeling exercise was to provide a systemic basis to support the dialogue on acceleration strategies. An acceleration strategy was defined as an activity plan (with one or more concrete activities), implicitly or explicitly directed towards the acceleration mechanisms as defined in ARTS. Here, activities may be TI-specific (for instance undertaking demonstration activities to increase their visibility, lobbying to influence local policies, partnering with other TIs to explore synergies etc.), and may also include policy instruments (incentives, funding mechanisms and other measures) that pertain to the city-regional level. For conceptually representing acceleration strategies, we drew from the concept of leverage points of a system [16]. Based on this, we conceptualize acceleration strategies as (sets of) of concrete activities directly influencing specific concepts in the STI model. With this conceptualization in mind, we search for and examine (within the empirical case study data gathered in every city region) purposeful and planned activities undertaken by the TIs that leverage acceleration mechanisms for sustainability transition. One example is the activity of demonstration and outreach aimed to increase the visibility of a TI, thereby leveraging on the mechanism of upscaling. Another example is the activity of lobbying that via an increase of support and influence leverages on the mechanism of embedding.

A first step in the analysis of acceleration strategies was to elicit strategies that were currently adopted in the different city regions by TIs and possibly other actors. To elicit these strategies, a strategy template was developed based on which the case study researchers described the characteristics of the different strategies adopted in their city region. The following key characteristics were elicited: strategy owner, the types of activities it pursues and to what end, and associated enablers and barriers. The inputs contributed by the regional teams provided a rich basis to work from (see [33]). The template was typically completed with some 20 to 50 different types of activities, mostly of TIs, but to some extent also of other actors. Elicited activities were consequently clustered into a suite of "activity types", each linked to one of the acceleration mechanism, and each influencing specific concepts in the STI model. For example, activities like organizing events, setting up training, and advertisement were clustered under the activity type "Demonstration and Outreach", linked to the acceleration mechanism of upscaling, with associated influences on the STI model concepts as described in Section 3.3. This clustering was originally done on the regional specific level, resulting in acceleration strategies linked to the case-study specific STI models. Afterwards, the clusters were integrated to provide a common typology of strategies linked to the generic STI model. 


\section{Results}

In the following we report our results. We first present the final version of the generic STI model, which is consequently used to illustrate key dynamics it represents, and the acceleration strategies that may be pursued. Both the key dynamics and acceleration strategies are further illustrated with examples from the case study of Genk [8].

\subsection{A Generic STI Model}

As the name implies, the main focus of the STI model is a single TI. The model focuses on the internal dynamics of a single TI, without an active representation of other regional actors (other TIs, governing bodies, etc.). Therefore, four of the core mechanisms (i.e., replicating, coupling, embedding, instrumentalizing) that would require the representation of such actors are only partly included in the conceptual scope of this model. They are included in terms of the capacity of a TI to interact with its city-regional context and other TIs, but not in terms of the "full" two-way interaction. The processes of interaction with other TIs and the city-regional context will be thoroughly addressed in a later stage while developing a multiple transition initiative (MTI) model. The STI model thus mainly relates to the first of four dimensions that are highlighted in the conceptual framework ("the development of single TIs within the city regions", see Section 2.2), and the processes covered in STI model are mainly related to mechanism of upscaling.

In the literature on social entrepreneurship and grassroots innovation [40-42], upscaling is generally associated with the spread of practices and increasing engagement in local initiatives. The conceptual framework consequently defines the upscaling of an initiative as the development of three actor groups [9]:

- Members: actors that comprise and establish the initiatives human capital, i.e., individuals involved in organizing the activities of the TI.

- Users: actors who participate in the TI activities, purchase or receive services from the TI.

- Supporters: actors who provide resources and/or supportive structures to initiatives at different stages of the initiatives' lifecycle or continuously, i.e., typically organizations like the city government, civil organizations or businesses.

The STI model therefore mainly focuses on major processes that alter the size of user, member and supporter basis of a TI. In other words, the model structure is woven around these three fundamental concepts. Table 1 gives an overview of the STI model by listing key dynamics included for each acceleration mechanism. The full CLD of the generic STI model is provided in Figure A1 of this article. Descriptions of all the concepts and relationships that are included in the model can be found in [33]. Figure A2 further presents the STI model that was developed specifically for the city region of Genk.

Table 1. Key dynamics included in the generic STI model for each acceleration mechanism.

\begin{tabular}{ll}
\hline \multicolumn{1}{c}{ Mechanism } & \multicolumn{1}{c}{ Key Dynamics in Generic STI Model } \\
\hline & $\begin{array}{l}\text { Increase (or decrease) of users, members and supporters due to higher (or lower) } \\
\text { perceived benefit by users, members and supports. }\end{array}$ \\
\cline { 2 - 2 } Upscaling & $\begin{array}{l}\text { Limits to growth of users, members, and supporters due to limited potential users, } \\
\text { members and supporters in the city region and competition for users, members } \\
\text { and support. }\end{array}$ \\
\cline { 2 - 2 } & $\begin{array}{l}\text { Perceived benefit for users reflects the benefits of adopting the sustainability practice, } \\
\text { with visibility of the practice and possible barriers of entry as further mitigating factors } \\
\text { for the change of users. }\end{array}$ \\
\cline { 2 - 2 } & $\begin{array}{l}\text { Perceived benefit for members, reflects besides the benefits of adopting the } \\
\text { sustainability practice, also the social and fulfillment benefits of being part of a TI. } \\
\text { Member overload (a too high workload for each member) may reduce those benefits. }\end{array}$ \\
\cline { 2 - 2 } & Perceived benefit by support can be stimulated through lobbying. \\
\hline
\end{tabular}


Table 1. Cont.

\begin{tabular}{|c|c|}
\hline Mechanism & Key Dynamics in Generic STI Model \\
\hline \multirow{3}{*}{ Replicating } & $\begin{array}{l}\text { Replication through sprouting dynamics (involving emigration of members) driven by } \\
\text { an increase of membership. }\end{array}$ \\
\hline & Internal and inward replication by inspiration (without emigration of members). \\
\hline & $\begin{array}{l}\text { Replication may lead to enhanced member, supporter and user competition by } \\
\text { increasing the number of similar initiatives in the region. }\end{array}$ \\
\hline \multirow{4}{*}{ Partnering } & Resource partnering, leading to an enhanced resource base. \\
\hline & Partnering for influence, leading to enhanced influence. \\
\hline & $\begin{array}{l}\text { Partnering for visibility: collaboration in setting up events and demonstrations, leading } \\
\text { to enhanced visibility. }\end{array}$ \\
\hline & Partnering for know-how: all exchanges to improve organizational skills. \\
\hline \multirow{3}{*}{ Embedding } & Embedding as an increase of formal and informal legitimacy. \\
\hline & $\begin{array}{l}\text { Drivers: increasing user base and demonstration and outreach-activities } \\
\text { (informal legitimacy) and Influence (formal legitimacy) }\end{array}$ \\
\hline & $\begin{array}{l}\text { Outcomes: Easier to generate resources (formal legitimacy) and an increase of } \\
\text { perceived benefit for users (informal legitimacy), as well as an increase of potential } \\
\text { available users in the region. }\end{array}$ \\
\hline \multirow{3}{*}{ Instrumentalizing } & Fund raising as a way to enhance resources. \\
\hline & $\begin{array}{l}\text { The effectiveness of fundraising depends among others on the organizational skills, } \\
\text { which can be enhanced through professionalization. }\end{array}$ \\
\hline & $\begin{array}{l}\text { Resources are a prerequisite for undertaking various activities, including management } \\
\text { activities, demonstration and outreach, lobbying etc. }\end{array}$ \\
\hline
\end{tabular}

\subsection{Key Dynamics Observed in the City regions}

The process of developing STI models supported a reflection on key acceleration dynamics that were commonly observed across city regions. For each acceleration mechanism, we highlight one key example.

\subsubsection{Upscaling}

In almost all city regions, a set of factors are identified as limiting the upscaling process for a TI, i.e., limits to growth. These limits seem to manifest themselves in various forms, but their basic nature is that they are outcomes of balancing (negative) feedback processes that counteract the upscaling of the TI. From this perspective, the reported limits to growth can be considered under three different categories:

- Intended internal limits: Some TIs are afraid of drifting away from their core values as a consequence of uncontrolled upscaling process. These TIs recognize a balance between preserving core values and growth in users/members. Therefore, they intentionally limit the growth of users/members. In other words, this is an organizational, internal limit set by the managing core team of the TI after observing the TI approaching a scale that is considered to be "ideal". As a TI approaches these limits, both existing and prospective users/members may evaluate the core values in decline due to overcrowding. This both may inhibit the inflow of new users/members, and trigger an outflow of existing ones (e.g., to initiate a new TI).

- Unintended internal limits: Upscaling is reported to bring in extra organizational, financial and managerial load on a TI. In the generic STI model, this limit is reflected through the influence of users on management activities and hence on the available time for activities related to core values. Therefore, unless the TI develops its organizational capacity (e.g., number of volunteers, organizational competencies) in parallel to upscaling, one may often observe a deterioration of the functioning of the organization. This would lead to a reduced perceived benefit for current 
and potentially new users and members, and a reduction of the growth of users/member, thus counteracting the upscaling process. Such a dynamic is very similar to the well-known systemic archetypes of growth and underinvestment [43].

- External limits: The third type of limits to growth results from the properties of the context within which the TI is functioning. Following the conceptual framework, three types of external limits are typically observed: member limits, user limits and support limits. The member limit implies that there is a limit to the amount of people willing and capable to engage as a TI member. The user limit implies that the new users will be constrained by the number of individuals in the city region who are willing to engage in sustainability practices. Similarly, a support limit results from the limited amount of resources available for supporting city-regional TIs. Apart from TIs being confined within a pool of potential users/members/supporters, the extents of these external limits are determined as a consequence of regional competition among TIs that rely on the same user/member/supporter pools.

In the city region of Genk, for example, the external member limit appears dominant. According to Gorissen et al. [8], upscaling is often hampered by "limits to growth", with many initiatives still struggling to grow beyond the already established sustainability scene (e.g., the environmentally conscious). Although more research on this topic is needed, one reason may be a relative lack of "entrepreneurship" in the city region, with limited people willing and capable to engage as TI members, in particular as initiators and TI leaders. The number of local people with the necessary entrepreneurial and organizational skills to enroll in a TI are rare. Rather than increasing their number of members, TIs thus put more emphasis on increasing users by attracting visitors.

\subsubsection{Replication}

When it comes to replication, it is possible to recognize two subtypes based on the way these unfold over time. In the first type, a successful TI acts as the source of inspiration for replication leaving it to others to adopt the idea under a new TI to be initiated. This form is referred to as either "internal" or "inward" replication depending on whether the TI that is the source of replication is based within or outside the city region. The second type involves a process of "sprouting". In that case, a set of members leaves an existing TI (for example triggered by the TI going beyond a certain scale) in order to establish a similar TI in the region. In both cases, a new TI that is similar to the older one in terms of the promoted practices emerges within the city region. In the former case, this replication has no imminent impact on the older TI, whereas it may lead to an immediate downscaling in the latter case. Although replication is considered to be a supporting mechanism for acceleration, there is empirical evidence that suggests a potential downside of it. In various case-study regions it is reported that the number of people in the region motivated and able to initiate and run a TI does not increase synchronous to the increasing number of TIs in the region. This may lead to a harsher regional competition among TIs for a limited pool of potential members (i.e., activating the external member limit).

Evidence from the city region of Genk shows that replication often occurs in response to inspiring initiatives beyond the city region, with actors external to Genk providing legitimacy and support (i.e., "inward" replication) [8]. There is no indication that TIs replicate because their membership base grows beyond a certain limit ("sprouting dynamics"). Replication usually involves the engagement of new members within the city region. As already mentioned above, the lack of "entrepreneurship" among the larger share of the Genk population and consequently the limited number of potential members is recognized as a barrier to replication.

\subsubsection{Partnering}

Empirical data from all four regions emphasize the trade-off regarding the partnering process by characterizing it as a time and resource consuming process with uncertain outcomes. In most cases, TIs do not consider partnering as a core activity, and perceive it as a secondary activity to 
engage in if the available time and resources allow after other core activities are carried out. The majority of the reported partnering instances are for sharing resources (generally physical space), transfer of knowledge (organizational), and creating a critical mass to foster visibility, with one report of partnering for increased TI influence. Despite these potential benefits, the motivation for partnering is often low and appears inversely correlated with the competition for supporters who are the main providers of resources in the city region. During more competitive times, the motivation of the TIs for partnering is reported to diminish.

In the city region of Genk, partnering was reported to be relatively strong. Various collaborations are observed [8], both between TIs, as well as between TIs and other actors (e.g., the municipality of Genk). Resource partnering is a main form of partnering observed through the sharing of facilities and infrastructures (see also [9]), and in one case the direct sharing of revenues among TIs. Another popular form of partnering is partnering for visibility; setting up common activities to showcase sustainability solutions to the wider public.

\subsubsection{Instrumentalizing}

Undertaking activities like management activities, demonstration and outreach, lobbying etc. requires resources (especially money and time). TIs may be dependent on external funding to sustain this capacity and activity level. Therefore, instrumentalization for financial resources stands as an important resource pool, with TIs being reported to benefit from funding streams at different levels (municipality level, city-regional level, national level, etc.). However, similar to partnering, instrumentalization is reported as a time intensive process with an uncertain level of success. Efficacy of a TI in benefiting from this mechanism seems to be influenced by it having the required organizational competence and experience (i.e., knowledge and capacity to seek and apply to funds). Therefore, professionalization leading to enhance organizational skills can yield positive outcomes regarding instrumentalization.

In Genk, TIs have been successful in drawing in subsidies via multiple sources: from city-regional and higher level (e.g., EU) funding schemes [8]. This city region provides an interesting example of how professionalization increases the changes of funding success. In Genk, the well-established links with district managers and community development professionals seem to have played a crucial role in this (as indicated by the link from supporters to instrumentalizing in the STI model for Genk). For example, they played an essential role in passing on valuable information about higher-level funding schemes and opportunities, and provided support (e.g., administrative or content wise) in acquiring the funding.

\subsubsection{Embedding}

The mechanism of embedding was probably most difficult to grasp in modeling terms. Two major aspects of the embedding process are commonly distinguished: informal and formal embedding. Informal embedding implies an increase in the extent to which the sustainability practice is recognized by the public at large as being appropriate and beneficial. In the STI model, informal embedding is driven by the number of users, under the assumption that the larger the number of users, the more acceptable the practice will be considered to be. In turn, it allows for the diffusion of sustainable practices to the public at large by increasing the potential number of users in the region. Formal legitimacy is the extent to which the sustainability practice is formally recognized (e.g., by the city government) as being appropriate, eventually reflected in supporting legislation, infrastructure and financial support. In the STI model, formal legitimacy is driven by the influence a TI has, with the level of users and supporters being the main determinants of influence.

Findings from the city region of Genk [8] indicate that embedding of environmental sustainability has been happening both formally and informally. Informal embedding occurs through the routinization and mainstreaming of sustainable solutions, in turn driven by the practices of the users of the TIs. Concerning formal embedding, TIs in Genk acknowledge that this is necessary 
because it grants legitimacy to the initiative and enables mobilization of resources. On the other hand however, they express the concern that formal embedding may lead to a loss of ownership and responsibility ("being taken over by the city"). This may potentially lead to a loss of benefits perceived by members, and hence a reduction of the membership base. This particular dynamic, however, was reported only for the Genk case and is therefore not included in the generic STI model.

\subsection{Acceleration Strategies Observed in the City Regions}

\subsubsection{The Nature of Acceleration Strategies}

According to our elicitation of acceleration strategies [33], TIs in our case-study city regions are generally not pursuing acceleration deliberately. TIs tend to pursue practical activities to improve their local community rather than think strategic beyond their everyday functioning. The notion of an acceleration strategy should therefore be interpreted with care, as it suggests a very deliberate way of pursuing a (sustainability related) end. Therefore, our analysis rather covers the concrete type of activities TIs undertake, as extracted from the empirical material. From our modeling perspective, these activities are linked to the particular concepts in the generic CLD on which they have a direct influence. This allows us to reflect on the possible impact of these activities regarding each of the five acceleration mechanisms, and on the tensions and challenges one may expect from the perspective of pursuing the acceleration of sustainability transition. These insights, in turn, are valuable to support the discussion on acceleration strategies.

For brevity, we illustrate this approach for the case of upscaling.

\subsubsection{The Case of Upscaling}

Table 2 presents a summary of the different types of observed activities that were related to the mechanism of upscaling, and how these link to specific concepts in the generic STI model of Annex A. We distinguish different types of activities as follows:

- Demonstration and Outreach activities are commonly observed across all regions. These are primarily aimed to increase the visibility of a TI and enhance the perceived benefit by users. In addition, they have impact on contextual factors like problem perception regarding the sustainability issue at hand.

- Professionalization is equally aimed at the TI itself, to enhance skills needed for fund raising and managing the TI. The professionalization activity relates to the internal organizational limit described before. As such, it may be a necessary element in any upscaling strategy to facilitate growth.

- Activities like Barrier Alleviation and Enhancing Attractiveness are typically aimed at the nature of the TI or practice itself and how it can be made more attractive or easier for users to enroll.

- Branding, finally, is specifically targeted towards visibility increase.

In Genk, for example, activities aimed at increasing visibility are key among the majority of TIs [33]. This is pursued by organizing and attending appealing demonstrations and events (demonstration \& outreach). In the same category, also advertisement is pursued through various channels (Facebook, magazine, presentations, workshops) although lack of computer and digital media skills remains a barrier. These actions are equally intended to "sensitize the general public" (i.e., to alter problem perceptions) regarding the particular issue at hand. Enhancing the attractiveness of a TI through user-friendly designs (like comfortable shop design or convenient opening hours) is also pursued by some TIs. 
Table 2. Activities and the concepts on which they have a direct influence for the case of upscaling. A "+" indicates a positive influence from the activity on the concept, a "-" indicates a negative influence.

\begin{tabular}{|c|c|c|c|c|c|c|c|c|}
\hline \multirow[t]{2}{*}{ Activities } & \multirow[t]{2}{*}{ Description } & \multicolumn{7}{|c|}{ Concepts Directly Influenced } \\
\hline & & $\begin{array}{l}\text { barrier of } \\
\text { entry }\end{array}$ & $\begin{array}{l}\text { benefits perceived by } \\
\text { supporters }\end{array}$ & $\begin{array}{l}\text { benefits perceived } \\
\text { by users }\end{array}$ & $\begin{array}{c}\text { formal } \\
\text { legitimacy }\end{array}$ & $\begin{array}{l}\text { organizational } \\
\text { skills }\end{array}$ & visibility & $\begin{array}{l}\text { problem } \\
\text { perception }\end{array}$ \\
\hline Professionalization & $\begin{array}{l}\text { Improving organizational, fundraising, } \\
\text { communication and other professional } \\
\text { skills. }\end{array}$ & & & & & + & & \\
\hline $\begin{array}{l}\text { Demonstration } \\
\text { and Outreach }\end{array}$ & $\begin{array}{l}\text { Demonstrations, events and advertisements } \\
\text { aiming to demonstrate the benefits of the } \\
\text { novelty being promoted by the initiative. }\end{array}$ & & & + & & & + & + \\
\hline Barrier Alleviation & $\begin{array}{l}\text { Alleviating barriers to becoming a user, } \\
\text { whether financial, cultural, language or } \\
\text { other barriers. }\end{array}$ & - & & & & & & \\
\hline $\begin{array}{l}\text { Enhancing } \\
\text { Attractiveness }\end{array}$ & $\begin{array}{l}\text { Makes becoming a user more attractive, for } \\
\text { example through user-friendly designs or } \\
\text { adding fun-elements. }\end{array}$ & & & + & & & & \\
\hline Branding & $\begin{array}{l}\text { Connecting the TI to a well-known brand } \\
\text { or organization. }\end{array}$ & & & & & & + & \\
\hline
\end{tabular}


For supporting upscaling, two observations can be made. First, we observe that many TIs undertake activities explicitly or implicitly directed towards upscaling. However, some TIs explicitly state not wanting to grow. For example, the pass-on shop in Genk expressed a clear preference not to grow [8]. This corresponds to the previously described "intended internal limit" and (the perception that growth could lead to moving away from core values) and unintended internal limits (the burden of extra organizational, financial and managerial load) described under Section 3.2. In the generic STI model, these limits are reflected through the influence of users on management activities and hence on the available time for activities related to core values, and through the concept of "overcrowding" where an increasing number of members reduces the perceived benefits to become a member. For setting out a more deliberate upscaling strategy, TIs would thus benefit from reflecting how these limits materialize and might be navigated for their specific case.

A second observation relates to the reported limit of engaging the general public in sustainability practices, scaling up beyond the "sustainability scene". This corresponds in particular to the external user and member limit described under Section 3.2. To overcome this limit, TIs could further reflect on possibilities for increasing the potential available users and members in the region. Rather than focusing on their individual visibility within (and constrained by) the current "sustainability scene", efforts could shift towards collaborative approaches to increase sustainability related problem perceptions within the city region, that could enable an extended growth of users and members for multiple TIs.

\section{Discussion}

In this article, we set out to take stock of the findings from conceptual and empirical work on the role of transition initiatives for accelerating transition as input for modeling acceleration dynamics. To this end, we focused on qualitatively modeling the dynamics of a generic single transition initiative (STI) evolving within its regional context. Through the modeling process, we framed both the observed acceleration dynamics (i.e., "how the system works"), as well as the adopted strategies (i.e., "how the system is influenced") from a modeling point of view.

A main added value of this modeling process is that it required us to frame dynamics in an unambiguous way, with precise definitions of concepts and influences. This provided a systematic basis for integrating insights on similar-yet subtly different-dynamics across case-study regions in a generic model. Additionally, the modeling process and modeling outcomes strengthened the analysis on interrelations between the mechanisms and added to the theoretical work of the acceleration phase of transition. The modeling process was iterative, in terms of eliciting data from the case study research and positioning new questions from the modeling to the stakeholder workshops contributing in this way in enriching data sets and understanding on the strategic agency in the acceleration of sustainability transition in city regions. As a con, the modeling process inherently required relatively high abstraction levels to find common concepts and influences that represent similar dynamics in the different regions in a comparable way. As such, we consider this approach complementary to qualitative empirical research methods with explicit benefit in enriching and strengthening theoretical and conceptual advancements of sustainability transition also applied in the ARTS project.

\subsection{Key Results}

The work presented in this article is primarily instrumental to the further modeling work. The insights presented in this article have been the basis for the development of an agent-based model representing the interaction among TIs in a more detailed and quantitative way. Furthermore, the agent-based model and the developed CLDs have been applied in a gaming setting with TIs and other stakeholders to further discuss acceleration dynamics and strategies [36]. Focusing here on the qualitative modeling approach as such, we see a number of key results: 


\subsubsection{Bridging Qualitative Research and Modeling}

The main achievement of this work we consider to be the further operationalization of the concept of acceleration from a modeling perspective complementary to conceptual work and case study analysis. Despite the limitations that a very qualitative and relational conceptualization of acceleration brings to the modeling work, this article shows how with a coherent and consistent operationalization one can connect a qualitative and social sciences definition to the modeling world. Our approach shows how goals (outcomes of interest) and activities can be related to the acceleration mechanisms in a very systematic way. The fact that the qualitative models and the strategies are based on in-depth case study data-also given the diversity of the cases—is an achievement.

\subsubsection{CLDs as Discussion Tools}

The CLDs developed provide a concise summary of the complex realities observed and described as part of the empirical analysis, and allow for a reflection on the system as a whole. As such, they can be used as discussion tools to support dialogue among researchers and the wider stakeholder community. The systematic structuring of acceleration strategies as activities influencing specific concepts in the overall system is useful to reflect on potentially effective acceleration strategies in terms of finding the most effective leverage points. A simplified version of the generic STI model has been implemented as such in gaming sessions with TIs and other stakeholders and were found to be a valid tool to engage the participants with the system behavior [36].

\subsubsection{Regional Comparison}

The case study specific CLDs and the analysis of acceleration strategies in the different city regions offers a systematic basis for comparing acceleration dynamics and strategies in different city-regional contexts. Overlaying the different regional CLDs can help to understand which dynamics are present in which regions and how this relates to the acceleration process overall. Such a regional comparison from a modeling perspective can further illustrate and explicate regional differences in acceleration dynamics.

\subsection{Main Limitations and Outlook}

Some main limitations and ways to address those are.

\subsubsection{Limitations Related to Empirical Model Validation}

The CLDs in this article and the inventory of strategies are based on the empirical work presented in Gorissen et al. [8], Frantzeskaki et al. [9] and Ehnert et al. [34], with additional input and reflection provided by the ARTS regional teams. However, our modeling effort often required data inputs that were not specifically focused on during the empirical work. For example, relations of influence were not elicited in detail. Also, limited data was available on the motivations underlying the activities the TIs undertake. Drawing up consistent CLDs thus required some level of interpretation and making sometimes bold assumptions. Consequently, the models provided in this article are meant to cover key dynamics and processes observed, but not considered empirically validated in detail. They are discussion tools, to be further elaborated on by the regional research teams and stakeholders.

\subsubsection{Limitations Related to Model Structure}

Models inherently can only partly represent the complex multi-faceted dynamics of real-life acceleration processes. Designing models that are sufficiently simple to be transparent and understandable, while at the same time covering those processes that can be considered "key" is a common challenge in modeling, not in the least when zooming in on a complex topic like accelerating transition. Moreover, a generic model—while useful for aggregating insights across case studies—can only partly represent the specific dynamics in the different city regions, even when a certain level of 
customization may take place. The appropriate level of complexity of the CLDs thereby depends on the specific application. If the aim is to provide a basis for further quantitative modeling (like the generic STI model presented in this article), the level of complexity can be relatively high. When the aim is to support discussion in a participatory context, the level of complexity needs to be reduced (see [36]) even when that implies a certain trade-off regarding the representation of acceleration dynamics.

\subsubsection{Treatment of Uncertainty}

The complexity of acceleration dynamics implies significant uncertainty in model structure and model parameters. Such uncertainty is often reflected in different perspectives stakeholders may have on the acceleration dynamics observed in their city region. The treatment of these uncertainties has not been at the forefront of our analysis. A way forward could be the development of perspective-based CLDs reflecting the acceleration dynamics as perceived by particular stakeholder groups (for example TIs versus regional authorities). Such an approach would make uncertainty more explicit in the dialogue on acceleration dynamics and strategies.

\subsubsection{From Single- to Multi-TI Model}

The modeling efforts have zoomed in on the dynamics of a single TI, whereas we need to move towards a multi-TI model to capture the relevant interactions between TIs and other actors. Although ample of consideration was given to the mechanism of partnering, other specific dynamics related to the interactions between TIs (for example competitive relationships) have thus been insufficiently covered. These mechanisms of interaction have been elaborated upon elsewhere $[35,36]$ through the development and application of an agent-based multiple transition initiative (MTI) model.

\subsubsection{Towards a Cross-Mechanism Analysis}

The current STI model and strategy analysis address each acceleration largely in isolation. In fact, the acceleration mechanisms provided a useful analytical tool to be able to address acceleration dynamics and strategies in a systematic way. A drawback, however, is that we have as yet not analyzed in detail how different acceleration mechanisms may interact. For example, how would upscaling influence the occurrence of partnering process? We have performed such analyses with the MTI model and through gaming applications as a next step [36].

\subsection{Conclusion}

The qualitative modeling approach provides a small step forward on the challenges of conceptualization and implementation and validation for transition modeling described in Holtz et al. [10]. The unique feature of the qualitative modeling approach is that it allows close interaction with conceptual and empirical case study work in the model design phase. Despite the limitations described above, the main advantage of this approach is ensuring that the model structure is sufficiently in line with realities as elicited from the case-study work. Whether-in the end-that leads to better transition models needs to be addressed further, by comparing the strengths and weaknesses of different types of approaches, and for different model purposes. At this stage we argue that the transition models developed on the basis of the qualitative modeling approach will have a higher potential as learning tools. Qualitative modeling as a first step helps to open the "black box" of transition model development, increasing model transparency. Moreover, by providing a visual description of the system dynamics it can support the reflection on transition model results as part of an interactive process with modelers, case-study researchers and stakeholders.

Acknowledgments: This article is based on research carried out as part of the ARTS Project, Accelerating and Rescaling Sustainability Transitions Project funded by the European Union's Seventh Framework Programme (FP7) (grant agreement 603654). We gratefully thank the whole project team for their contributions to this work. 
Author Contributions: Pieter Valkering, Gönenç Yücel, Ernst Gebetsroither-Geringer and Karin Markvica were responsible for the modelling work and developing the causal loop diagrams; Niki Frantzeskaki coordinated the conceptual work and the case study analyses; Erika Meynaerts worked on the case study of Genk; all authors contributed to the paper.

Conflicts of Interest: The authors declare no conflicts of interest.

\section{Appendix A}

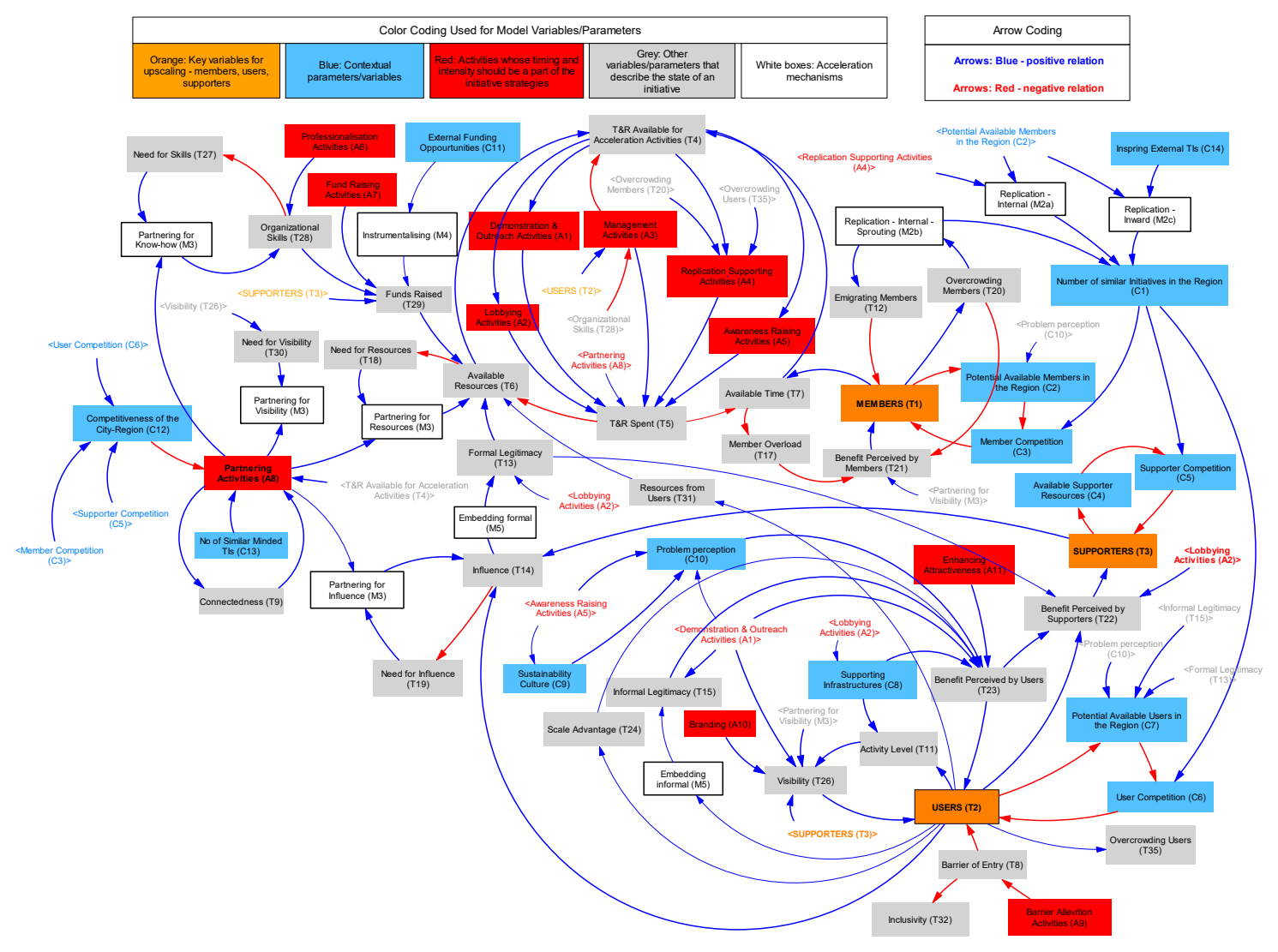

Figure A1. Generic STI Model. 


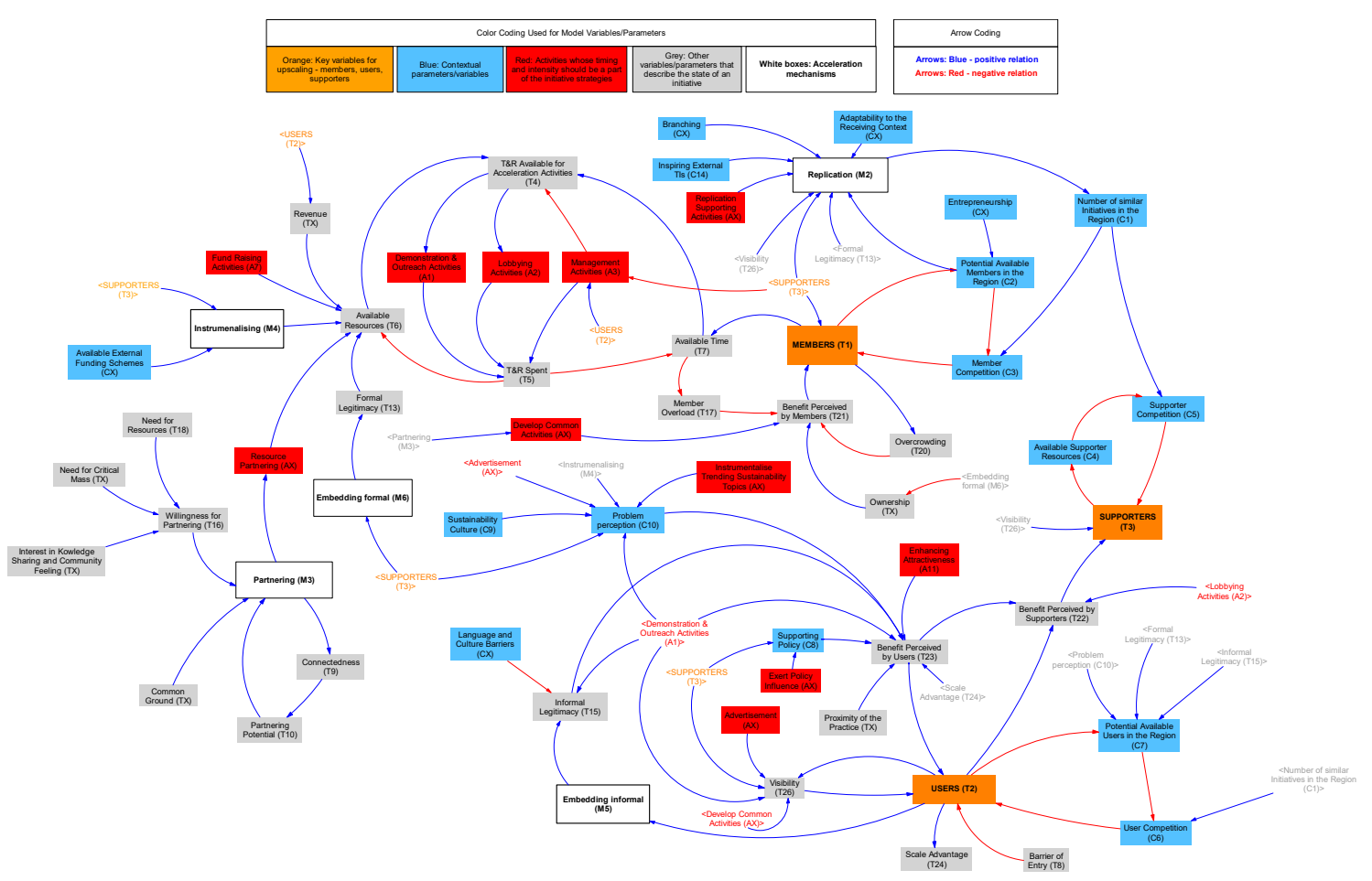

Figure A2. STI Model for the City Region of Genk.

\section{References}

1. Frantzeskaki, N.; de Haan, H. Transitions: Two steps from theory to policy. Futures 2009, 41, 593-606. [CrossRef]

2. Rotmans, J.; Kemp, R.; Asselt, M.V. More evolution than revolution: Transition management in public policy. Foresight 2001, 3, 1-17. [CrossRef]

3. Van der Brugge, R.; Rotmans, J. Towards transition management of European water resources. Water Resour. Manag. 2007, 21, 249-267. [CrossRef]

4. Raven, R. Niche accumulation and hybridisation strategies in transition processes towards a sustainable energy system: An assessment of differences and pitfalls. Energy Policy 2007, 25, 2390-2400. [CrossRef]

5. Smith, A.; Raven, R. What is protective space? Reconsidering niches in transitions to sustainability. Res. Policy 2012, 41, 1025-1036. [CrossRef]

6. Van Buuren, A.; Loorbach, D. Policy innovation in isolation? Conditions for policy renewal by transition arenas and pilot projects. Public Manag. Rev. 2009, 11, 375-392. [CrossRef]

7. Frantzeskaki, N.; Dumitru, A. Elucidating the changing roles of civil society in urban sustainability transitions. Curr. Opin. Environ. Sustain. 2016, 22, 41-50. [CrossRef]

8. Gorissen, L.; Spira, F.; Meynaerts, E.; Valkering, P.; Frantzeskaki, N. Moving towards systemic change? Investigating acceleration dynamics of urban sustainability transitions in the Belgian City of Genk. J. Clean. Prod. 2016. [CrossRef]

9. Frantzeskaki, N.; Borgstrom, S.; Gorissen, L.; Egermann, M.; Ehnert, F. Nature-based Solutions to Climate Change Adaptation in Urban Areas-Linkages between Science, Policy and Practice. In Nature-Based Solutions Accelerating Urban Sustainability Transitions in Cities; Kabisch, N., Korn, H., Stadler, J., Bonn, A., Eds.; Springer: Berlin, Germany, 2017.

10. Holtz, G.; Alkemade, F.; de Haan, F.; Köhler, J.; Trutnevyte, E.; Luthe, T.; Halbe, J.; Papachristos, G.; Chappin, E.; Kwakkel, J.; et al. Prospects of modelling societal transitions: Position paper of an emerging community. Environ. Innov. Soc. Transit. 2015, 17, 41-58. [CrossRef]

11. Li, F.G.N.; Trutnevyte, E.; Strachan, N. A review of socio-technical energy transition (STET) models. Technol. Forecast. Soc. Chang. 2015, 100, 290-305. [CrossRef] 
12. Halbe, J.; Reusser, D.E.; Holtz, G.; Haasnoot, M.; Stosius, A.; Avenhaus, W.; Kwakkel, J.H. Lessons for model use in transition research: A survey and comparison with other research areas. Environ. Innov. Soc. Transit. 2014, 15, 194-210. [CrossRef]

13. Turnheim, B.; Berkhout, F.; Geels, F.; Hof, A.; McMeekin, A.; Nykvist, B.; van Vuuren, D. Evaluating sustainability transitions pathways: Bridging analytical approaches to address governance challenges. Glob. Environ. Chang. 2015, 35, 239-253. [CrossRef]

14. Geels, F.W.; Berkhout, F.; van Vuuren, D.P. Bridging analytical approaches for low-carbon transitions. Nat. Clim. Chang. 2016, 6, 576-583. [CrossRef]

15. Moallemi, E.A.; Aye, L.; de Haan, F.J.; Webb, J.M. A dual narrative-modelling approach for evaluating socio-technical transitions in electricity sectors. J. Clean. Prod. 2017. [CrossRef]

16. Meadows, D.H. Leverage points: Places to intervene in a system. Sustain. Inst. 1999, 91, 78-84.

17. Rotmans, J. Societal innovation: Between dream and reality lies complexity. Inaugural speech, Erasmus University Rotterdam: Rotterdam, The Netherlands, 2005.

18. Geels, F.W.; Schot, J. Typology of sociotechnical transition pathways. Res. Policy 2007, 36, 399-417. [CrossRef]

19. Loorbach, D. Transition Management: New Mode of Governance for Sustainable Development. Ph.D. Thesis, Erasmus University Rotterdam, Rotterdam, The Netherlands, 2007.

20. Chappin, E.J.L. Simulating Energy Transitions. Ph.D. Thesis, Delft University of Technology, Delft, The Netherlands, 2011.

21. Dijk, M.; Kemp, R.; Valkering, P. Incorporating social context and co-evolution in an innovation diffusion model-With an application to cleaner vehicles. J. Evol. Econ. 2013, 23, 295-329. [CrossRef]

22. Li, F.G.N.; Strachan, N. Modelling energy transitions for climate targets under landscape and actor inertia. Environ. Innov. Soc. Transit. 2016. [CrossRef]

23. De Haan, F.J.; Rogers, B.C.; Brown, R.R.; Deletic, A. Many roads to Rome: The emergence of pathways from patterns of change through exploratory modelling of sustainability transitions. Environ. Modell. Softw. 2016, 85, 279-292. [CrossRef]

24. Walrave, B.; Raven, R. Modelling the dynamics of technological innovation systems. Res. Policy 2016, 45, 1833-1844. [CrossRef]

25. Bergman, N.; Haxeltine, A.; Whitmarsh, L.; Kohler, J.; Schilperoord, M.; Rotmans, J. Modelling Socio-Technical Transition Patterns and Pathways. J. Artif. Soc. Soc. Simul. 2008, 11, 7.

26. Haxeltine, A.; Whitmarsh, L.; Bergman, N.; Rotmans, J.; Schilperoord, M.; Kohler, J. A Conceptual Framework for transition modelling. Int. J. Innov. Sustain. Dev. 2008, 3, 93-114. [CrossRef]

27. Schilperoord, M.; Rotmans, J.; Bergman, N. Modelling societal transitions with agent transformation. Comput. Math. Organ. Theory 2008, 14, 283-301. [CrossRef]

28. Köhler, J.; Whitmarsh, L.; Nykvist, B.; Schilperoord, M.; Bergman, N.; Haxeltine, A. A transitions model for sustainable mobility. Ecol. Econ. 2009, 68, 2985-2995. [CrossRef]

29. Yücel, G. Analyzing Transition Dynamics. The Actor-Option Framework for Modelling Socio-Technical Systems. Ph.D. Thesis, Delft University of Technology, Delft, The Netherlands, 2010.

30. Yücel, G.; Meza, C.M.C. Studying Transition Dynamics via Focusing on Underlying Feedback Interactions. Comput. Math. Organ. Theory 2008, 14, 320-349. [CrossRef]

31. Yücel, G.; van Daalen, C. Understanding the Dynamics Underlying the Waste Management Transition. In Proceedings of the IASTED Applied Simulation and Modelling Conference, Corfu, Greece, 23-25 June 2008.

32. Yücel, G.; van Daalen, C. A simulation-based analysis of transition pathways for the Dutch electricity system. Energy Policy 2012, 42, 557-568. [CrossRef]

33. ARTS. Acceleration Dynamics and Strategies: A Modelling Perspective. Meta-Model Structure for the Regional Strategy Exploration Models. ARTS Deliverable 4.1. 2016. Available online: http:/ / www.ie.boun. edu.tr/sites/default/files/ARTS_D41.pdf (accessed on 13 July 2017).

34. Ehnert, F.; Kern, F.; Borgström, S.; Gorissen, L.; Maschmeyer, S.; Egermann, M. Urban Sustainability Transitions in a Context of Multi-level Governance: A Comparison of Four European States. Environ. Innov. Soc. Transit. 2017. [CrossRef]

35. ARTS. Exploring the Interaction among Transition Initiatives and its Impact on Accelerating Regional Transition. The Multi Transition Initiative Model. ARTS Deliverable 4.2. 2016. Available online: http: / / www.ie.boun.edu.tr/sites/default/files/ARTS_D42.pdf (accessed on 13 July 2017). 
36. ARTS. Model and Gaming Based Exploration of Acceleration Dynamics and Strategies. ARTS Deliverable 4.3 \& 4.4. 2016. Available online: http://www.ie.boun.edu.tr/sites/default/files/ARTS_D43_D44.pdf (accessed on 13 July 2017).

37. Voinov, A.; Bousquet, F. Modelling with stakeholders. Environ. Modell. Softw. 2010, 25, 1268-1281. [CrossRef]

38. Van der Wal, M.M.; de Kraker, J.; Kroeze, C.; Kirschner, P.A.; Valkering, P. Can computer models be used for social learning? A serious game in water management. Environ. Modell. Softw. 2016, 75, 119-132. [CrossRef]

39. Yin, R.K. Case Study Research: Design and Methods; Sage Publications: Thousand Oaks, CA, USA, 1994.

40. Desa, G.; Koch, J.L. Scaling social impact: Building sustainable social ventures at the base-of-the-pyramid. J. Soc. Entrep. 2014, 5, 146-174. [CrossRef]

41. Boyer, R.H.W. Grassroots innovation for urban sustainability: Comparing the diffusion pathways of three ecovillage projects. Environ. Plan. A 2015, 45, 320-337. [CrossRef]

42. Staggenborg, S.; Ogrodnik, C. New environmentalism and transition Pittsburgh. Environ. Politics 2015, 24, 723-741. [CrossRef]

43. Senge, P.M. The Fifth Discipline: The Art and Practise of the Learning Organization; Doubleday: New York, NY, USA, 1990.

(C) 2017 by the authors. Licensee MDPI, Basel, Switzerland. This article is an open access article distributed under the terms and conditions of the Creative Commons Attribution (CC BY) license (http://creativecommons.org/licenses/by/4.0/). 